\title{
Ethyl acetate extract of Chinese medicinal herb Sarcandra glabra induces growth inhibition on human leukemic HL-60 cells, associated with cell cycle arrest and up-regulation of pro-apoptotic Bax/Bcl-2 ratio
}

\author{
W.Y.LI, LAWRENCE C.M. CHIU, W.S. LAM, W.Y. WONG, Y.T. CHAN, Y.P. HO, \\ ELAINE Y.L. WONG, Y.S. WONG and VINCENT E.C. OOI
}

Department of Biology, The Chinese University of Hong Kong, Shatin, Hong Kong, P.R. China

Received May 3, 2006; Accepted July 28, 2006

\begin{abstract}
Sarcandra glabra (Thunb.) Nakai, colloquially known as Caoshanhu, is a Chinese medicinal herb with reported anti-tumor, anti-inflammatory, anti-viral and nonspecific immunoenhancing properties. Although the plant has been clinically used for treating a variety of diseases, its bioactive ingredients are largely unknown and its mode of action has never been investigated. In this study, the antitumor property of ethyl acetate (EA) extract of S. glabra was investigated by determining its in vitro growth-inhibitory effects on a panel of human cancer cell lines of different histotypes. Growth inhibition of the EA extract on the cancer cells seemed to be selective, and the leukemic HL-60 was found to be the most responsive after $48 \mathrm{~h}$ of treatment $\left(\mathrm{IC}_{50}=58 \mu \mathrm{g} / \mathrm{ml}\right)$. Flow cytometric studies further illustrated that the extract might interfere with DNA replication and thus arrested the cell cycle at $\mathrm{S}$ phase in the leukemic cells, followed by DNA fragmentation and loss of phospholipid asymmetry in the plasma membrane after $72 \mathrm{~h}$ of treatment. Concurrently, the pro-apoptotic $\mathrm{Bax} / \mathrm{Bcl}-2$ ratio was also up-regulated by more than $178 \%$ of the control level. All these findings suggested that the extract had initiated apoptosis to kill the leukemic cells. Results from this pioneer study help to establish a scientific foundation for future research and development of the bioactive ingredients in EA extract of S. glabra as efficacious anti-cancer agents.
\end{abstract}

\section{Introduction}

Natural products have become increasingly important for new pharmaceutical discoveries (1). Among all the uses for natural

Correspondence to: Dr Lawrence C.M. Chiu, Natural Product and TCM Pharmacology Research Laboratory, Department of Biology, The Chinese University of Hong Kong, Shatin, N.T., Hong Kong, P.R. China

E-mail: chimingchiu@graduate.hku.hk

Key words: Chinese medicine, Sarcandra glabra, HL-60, cell cycle arrest, apoptosis products in biomedical science, traditional Chinese herbology has been one of the pioneers. Sarcandra glabra (Thunb.) Nakai, a plant belonging to the family, Chloranthaceae, is a medicinal plant in traditional herbal formulations (2-5). S. glabra is well-known for its potency against various kinds of cancer together with non-specific immunoenhancement effects, and has been used clinically in mainland China as an important anti-cancer agent $(2,6)$. Its effect is especially prominent in leukemia, pancreatic cancer, and cancers of the gastrointestinal tract, such as stomach and colon cancers (3), and the plant has been used as complementary to conventional cancer therapies. Despite the clinical popularity of S. glabra as an anti-cancer agent in China, the anti-cancer mechanisms of its bioactive components have never been investigated.

Programmed cell death, or apoptosis, is an important regulatory mechanism that controls cell number as part of normal development (7) and the occurrence of cancer has been regarded as a pathological condition that is closely related to the deregulation of apoptosis (8). Therefore, targeting the apoptotic signaling pathways has been highly focused in cancer therapy research. Apoptosis is distinguished from other types of cell death by its unique morphological and biochemical features, such as cytoplasmic condensation, apoptotic body formation, loss of cell membrane phospholipid asymmetry and internucleosomal fragmentation of genomic DNA (9-11). The execution of apoptosis, on the other hand, is tightly regulated by well-organized signaling pathways. The proteins of the $\mathrm{Bcl}-2$ family constitute the major components in the apoptotic signaling cascades (12). This family of proteins regulates mitochondrial membrane permeabilization (MMP) (13-16), so that when the outer mitochondrial membrane becomes perforated, the key effectors of apoptosis, such as cytochrome $c$, are released from the intermembrane space of mitochondria to the cytosol (15). Bcl-2 is one of the anti-apoptotic members of this family and is a membrane protein that integrates in the outer membrane of mitochondria and other organelles $(12,17,18)$. It protects cells from apoptosis induced by the removal of survival factors and the cytocidal effects of various cytotoxic agents, by stabilizing the mitochondrial membrane (19-21). Bax, on the other hand, is one of the pro-apoptotic members that accelerates apoptosis. Bax is capable of inducing mitochondrial membrane 
depolarization and cytochrome $c$ release, both destabilizing the functions of mitochondria $(12,22,23)$. The triggering of apoptosis therefore depends on the balance between the proand anti-apoptotic members inside the cells (15). For instance, a high $\mathrm{Bax} / \mathrm{Bcl}-2$ ratio favors cell death and vice versa $(12,24)$.

In this study, ethyl acetate (EA) extract was prepared from S. glabra, and its effects on inhibiting cell proliferation and viability of human cancer cell lines of various histotypes were investigated. We report here the first evidence that the bioactive components in the EA extract of $S$. glabra induce cell cycle arrest at $S$ phase in human promyelocytic leukemic HL-60 cells, followed by apoptosis induction and upregulation of the pro-apoptotic $\mathrm{Bax} / \mathrm{Bcl}-2$ ratio. Results from this study help to establish a scientific foundation for the anti-cancer property of S. glabra. Since S. glabra is an inherently safe herb (3), which has a long history of being used in traditional herbal formulations in China, some novel, safer and even more efficacious anti-cancer components may be developed from it in the near future.

\section{Materials and methods}

Sarcandra glabra and chemicals. The dried whole plant of S. glabra herb was obtained as short fragments from a renowned TCM retailer in Hong Kong. The herb was then authenticated by Professor S.Y. Hu, the botanist of the Department of Biology, The Chinese University of Hong Kong. Voucher specimens were also deposited at the herbarium at the location stated above. Cell culture media, Fungizome $^{\circledR}$, and penicillin-streptomycin were obtained from Gibco BRL, Gaithersberg, MD. All the solvents used in extraction and fractionation of $S$. glabra were provided by Labscan Analytical, Bangkok, Thailand. Bcl-2 and Bax antibodies, horseradish peroxidase (HRP)-conjugated secondary antibody, and LumiGLO ${ }^{\circledR}$ substrate were obtained from Cell Signaling Technology, Beverly, MA. A fluorescein isothiocyanate (FITC)-conjugated annexin V apoptosis detection kit was provided by Immunotech, Marseille, France. All the other chemicals used, unless otherwise stated, were provided by Sigma Chemicals, St. Louis, MO.

Cell cultures. All six cancer cell lines used in this study were originally obtained from the American Type Culture Collections (Rockville, MD), and cultured according to the conditions suggested by the company. Human acute leukemia HL-60, breast carcinoma MCF-7 and hepatocellullar carcinoma HepG2 were grown in RPMI-1640 medium; human prostate carcinoma PC-3 and lung carcinoma A549, in F12K; and melanoma A375, in DMEM. All cell cultures were supplemented with $0.2 \%$ sodium bicarbonate, $10 \%$ heat inactivated fetal bovine serum (Hyclone, Logan, UT), $0.1 \%$ Fungizome, and $1 \%$ penicillin-streptomycin, and were then incubated at $37^{\circ} \mathrm{C}$ in $5 \% \mathrm{CO}_{2}$ under fully humidified conditions.

Extraction and fractionation of Sarcandra glabra. The dried whole plant of $S$. glabra was ground with a mechanical grinder. The ground fragments $(100 \mathrm{~g})$ were then immersed in methanol at room temperature for 6 days, with replacement of fresh methanol every 3 days. Dissolved constituents were completely dried into powders under vacuum at $40^{\circ} \mathrm{C}$ in a rotary evaporator for $2 \mathrm{~h}$ and in a desiccator for 1 day $(0.5 \mathrm{~g})$. The dried methanol extract was then re-suspended in $10 \mathrm{ml}$ of distilled water, making up the lower aqueous phase in a pear-shaped separating funnel. Corresponding organic solvent (upper organic phase) was added for partitioning for $1 \mathrm{~h}$. After reaching phase equilibrium, the organic phase was separated and kept as an extract for further studies and the remaining aqueous phase was partitioned once more with another more hydrophilic organic solvent in consecutive stages of extraction. Four organic solvents, in increasing order of polarity; petroleum ether, chloroform, ethyl acetate, and butan-1-ol, were subsequently partitioned in the separating funnel. The final portion, after all partitioning, was the aqueous residue fraction. Dried extracts obtained from each of the petroleum ether, chloroform, ethyl acetate, and butan-1-ol fractions were weighed $(0.05 \mathrm{~g})$, while extract obtained from the aqueous residue was weighed $(0.3 \mathrm{~g})$. In this study, only the EA extract was investigated by re-dissolving it in dimethyl sulphoxide (DMSO) as a stock solution of $100 \mathrm{mg} / \mathrm{ml}$.

Growth-inhibition assays. The leukemic HL-60 cells were plated in a round-bottom 96-well microtitre plate at $1 \times 10^{4}$ cells/ well. The stock solution of EA extract was then serially diluted and added to the cells to attain a final concentration of 0.78 $200 \mu \mathrm{g} / \mathrm{ml}$. Treatment with $0.2 \%$ DMSO was included as vehicle control. The plate was then incubated for $48 \mathrm{~h}$, and the number of viable cells was determined with the aid of a haemocytometer and a trypan blue exclusion test. The average number of viable cells per unit volume of culture medium, i.e., cell density, was then calculated.

For adherent cancer cells, 3-(4,5-dimethylthiazol-2-yl)2,5-diphenyl tetrazolium bromide (MTT)-based assay was used. The cancer cells were plated in a flat-bottom 96-well microtitre plate at $5 \times 10^{3}$ cells/well. After $24 \mathrm{~h}$ of acclimatization, serially-diluted EA extract, $0.78-200 \mu \mathrm{g} / \mathrm{ml}$, was incubated with the cells for $48 \mathrm{~h}$. Treatment with $0.2 \%$ DMSO was included as vehicle control. After $48 \mathrm{~h}$ of incubation, the cells were subjected to MTT assay. MTT solution was freshly prepared by dissolving MTT reagent in sterilized PBS (5 mg/ $\mathrm{ml})$. Twenty microliters of MTT solution was then added to each well of the plate and incubated at $37^{\circ} \mathrm{C}$ in $5 \% \mathrm{CO}_{2}$. After $5 \mathrm{~h}$ of incubation, $150 \mu \mathrm{l}$ acid-isopropanol $(0.04 \mathrm{~N} \mathrm{HCl})$ was added to each aspirated well to dissolve the remaining blue formazan crystals. Absorbance of the blue formazan solution was then measured by a microplate reader at $570 \mathrm{~nm}$ after thorough mixing.

Cell cycle analysis by flow cytometry. After treatment, $1 \times 10^{6}$ HL-60 cells were fixed overnight at $-20^{\circ} \mathrm{C}$ with $70 \%$ ethanol. The fixed cells were then washed with PBS twice before being re-suspended in $1 \mathrm{ml}$ PBS, containing $0.05 \mathrm{mg} / \mathrm{ml}$ RNase A and $10 \mathrm{mg} / \mathrm{ml}$ propidium iodide (PI). The cell suspension was then incubated in the dark for $30 \mathrm{~min}$. The stained cells were finally analysed with EPICS XL-MCL flow cytometer (Beckman Coulter, Miami, FL). The red fluorescence of PI was measured at $>625 \mathrm{~nm}$. Cell cycle was then analysed by MultiCycle software (Phoenix Flow Systems, San Diego, CA). 
(A)
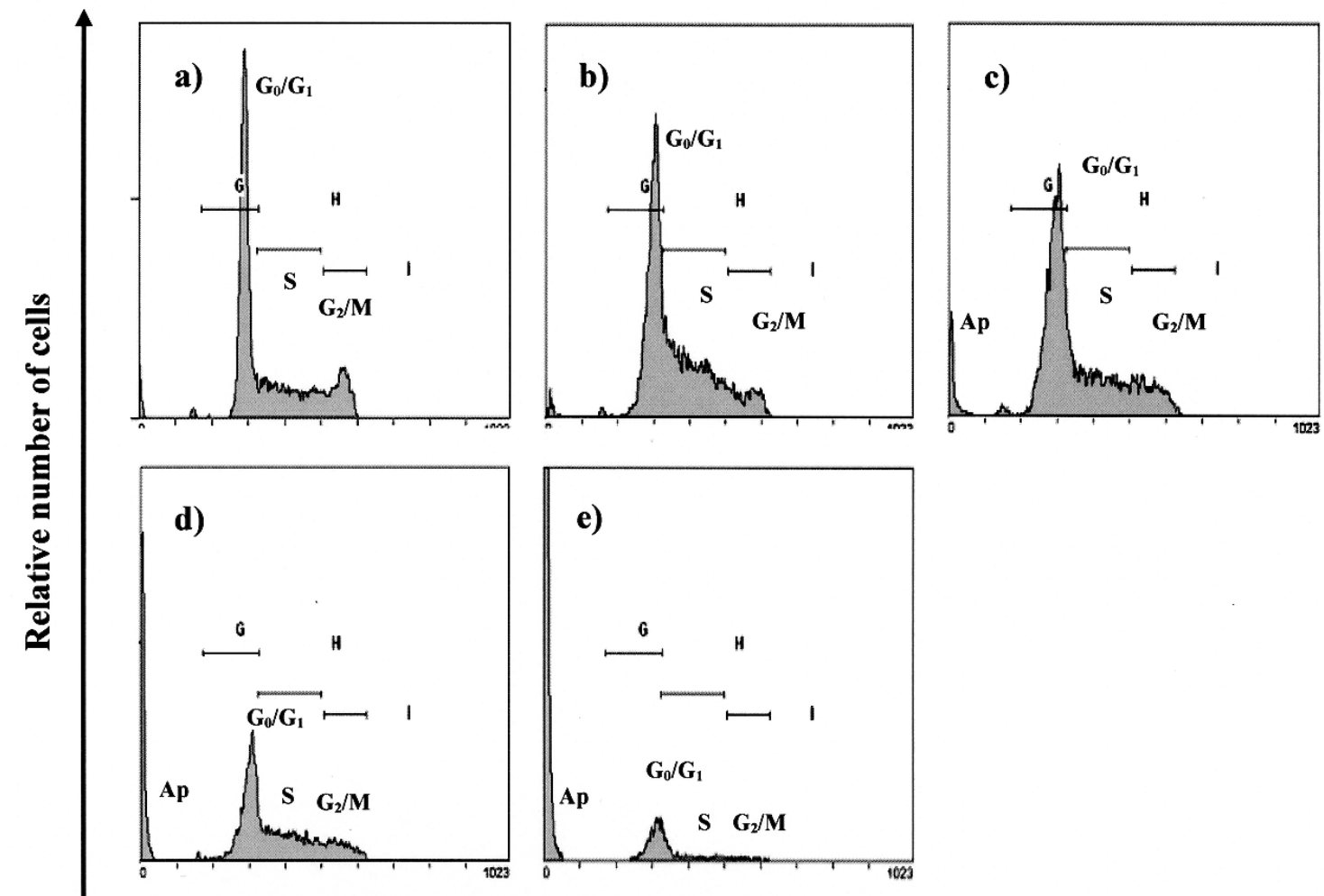

Fluorescence from PI (DNA content)

(B)

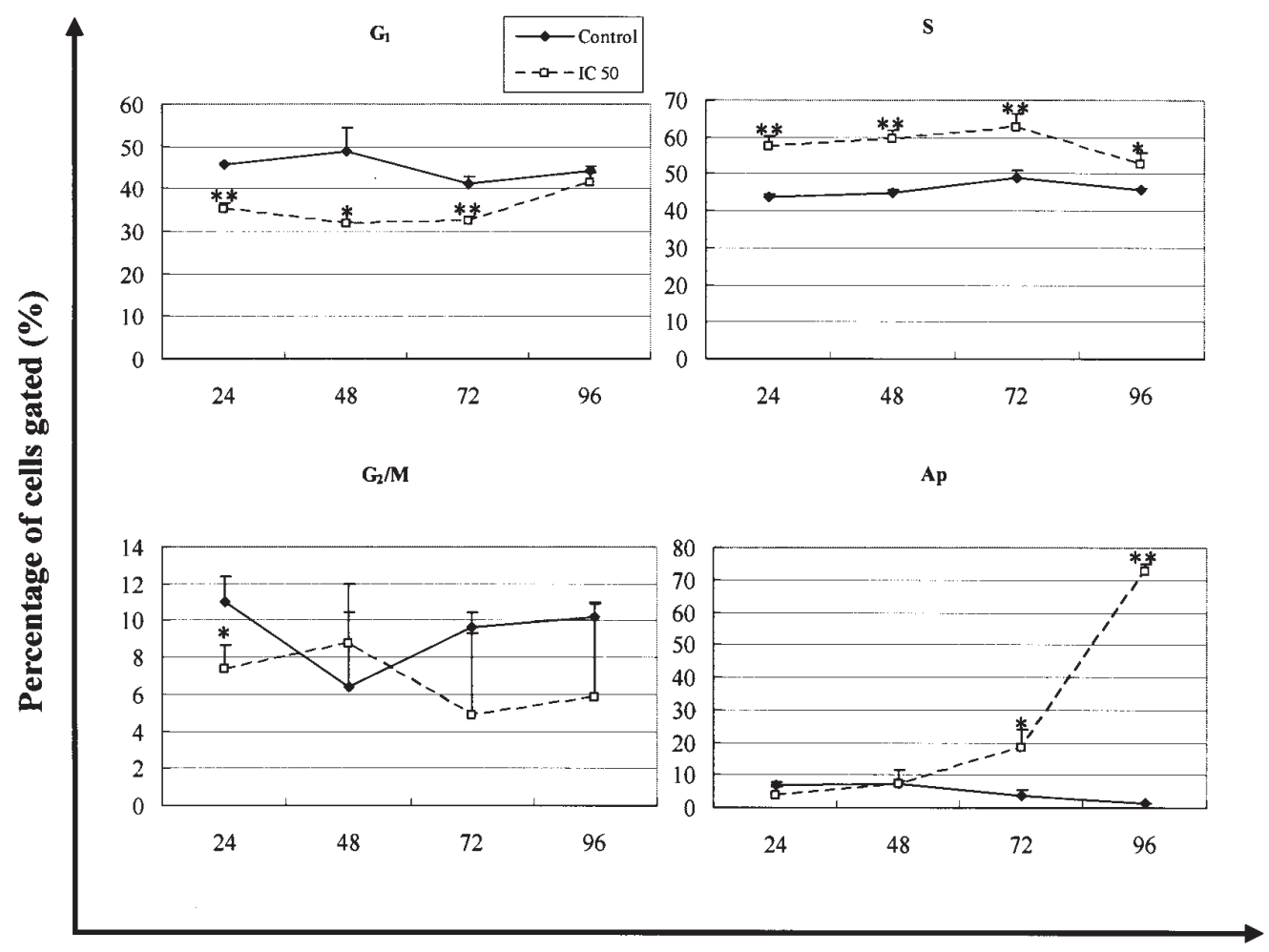

\section{Incubation time (h)}

Figure 1. Effects of the EA extract of S. glabra on cell cycle and apoptosis in HL-60 cells. (Panel A) Representative DNA histograms from DNA-PI flow cytometry showing cell cycle and apoptosis in the leukemic cells after incubation in the absence, control (a), or in the presence of the EA extract at $\mathrm{IC}_{50}$ for $24 \mathrm{~h}$

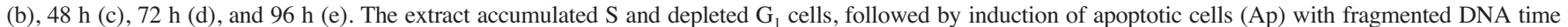
dependently. (Panel B) Proportion of $\mathrm{G}_{1}, \mathrm{~S}, \mathrm{G}_{2} / \mathrm{M}$, and apoptotic cells at different times of treatment with the EA extract. Results are expressed as mean \pm SD of three independent experiments. ${ }^{*} \mathrm{p}<0.05$ and ${ }^{* *} \mathrm{p}<0.01$, compared to the corresponding time control by Student's t-test. 
Table I. $\mathrm{IC}_{50}$ values of the EA extract of $S$. glabra on different human cancer cell lines.

\begin{tabular}{llr}
\hline Cell line & \multicolumn{1}{c}{ Histotype } & $\mathrm{IC}_{50}(\mu \mathrm{g} / \mathrm{ml})$ \\
\hline A375 & Melanoma & 175 \\
A549 & Lung carcinoma & $>1000$ \\
HepG2 & Hepatocellular carcinoma & 490 \\
MCF-7 & Breast carcinoma & 309 \\
PC-3 & Prostate carcinoma & $>1000$ \\
HL-60 & Acute promyelocytic leukemia & 58 \\
\hline
\end{tabular}

Bivariate annexin V/PI flow cytometry. All procedures were followed as stated in the manual of the apoptosis detection kit (Immunotech, Marseille, France). Briefly, the treated HL-60 cells were centrifuged and washed with $3 \mathrm{ml}$ ice-cold PBS twice before being re-suspended in the provided binding buffer at density $1 \times 10^{6}$ cells $/ \mathrm{ml}$. One hundred microliters of the cell suspension were then stained with $5 \mu 1$ FITCconjugated annexin $\mathrm{V}$ and $2 \mu \mathrm{l}$ PI (both were provided with the kit) for $20 \mathrm{~min}$ in the dark at room temperature. The stained cell suspension was then diluted with $400 \mu 1$ of the binding buffer before being subjected to flow cytometry analysis. Green fluorescence from FITC and red fluorescence from PI were then measured at $525 \mathrm{~nm}$ and $>625 \mathrm{~nm}$ respectively by the flow cytometer.
Western-blot analysis. The treated HL-60 cells were lysed, and the protein content of the cell lysate was determined by the standard bicinchonic acid (BCA) assay. Fifty micrograms of the proteins were then resolved by SDS-PAGE and transferred onto a nitrocellulose membrane (Amersham Life Science, Burkinghamshire, UK) by electroblotting. The membrane was first blocked with $0.2 \%$ Aurora ${ }^{\circledR}$ blocking reagent (ICN Biomedicals, OH) and 0.1\% Tween-20 solution. Bcl-2 or Bax antibody was then incubated with the membrane for $1 \mathrm{~h}$ with shaking at room temperature. $B$-actin was also measured as loading control. The membrane was then washed and incubated with HRP-conjugated goat secondary antibody for $1 \mathrm{~h}$ at room temperature. The washed membrane was incubated with $10 \mathrm{ml}$ LumiGLO substrate. Protein bands on the membrane were finally visualized by X-ray film exposure. A densitometer was used to scan and quantify the intensity of the protein bands in arbitrary units.

Statistical analysis. The difference in means between the control and experimental groups from three independent experiments was compared using the two-tailed Student's ttest, $\mathrm{p}<0.05$.

\section{Results}

The EA extract of Sarcandra glabra inhibits human cancer cell growth. In this study, the in vitro growth-inhibitory effect

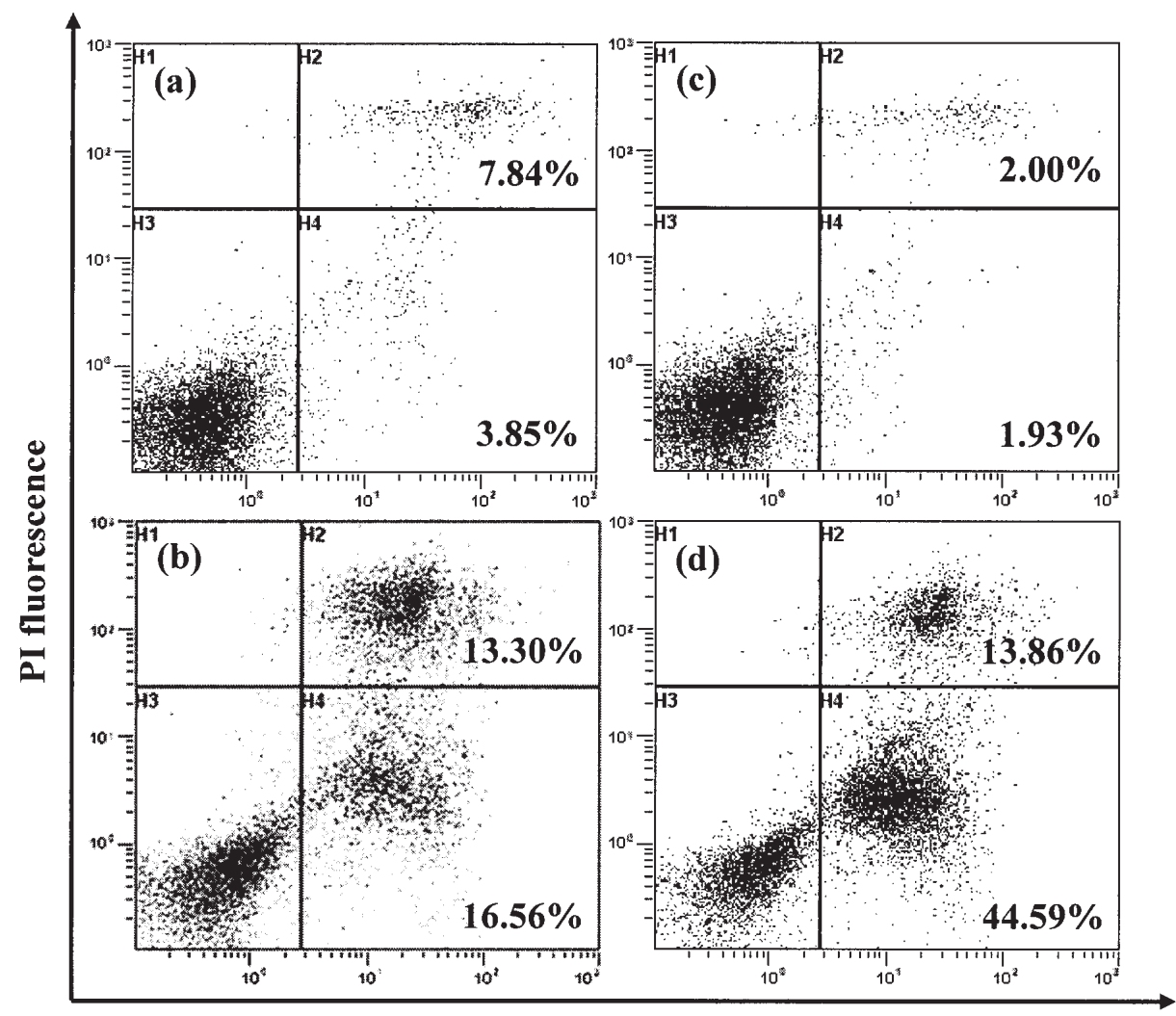

FITC fluorescence

Figure 2. Representative bivariate dot plots from annexin V/PI flow cytometry showing pro-apoptotic effect of the EA extract on HL-60 cells. At 48 h of treatment with the EA extract at $\mathrm{IC}_{50}$, both early phase apoptotic cells in quadrant $\mathrm{H} 4$ and late phase apoptotic cells (or necrotic cells) in quadrant $\mathrm{H} 2$ were prominently elevated (b), compared to the control (a). The pro-apoptotic effect of the extract increased time dependently, so that at $72 \mathrm{~h}$ of treatment even more apoptotic and necrotic cells were found in the treated group (d) than in the control group (c). Proportion of total analyzed cells undergoing early-phase and late-phase apoptosis are also shown. 
of the EA extract of $S$. glabra was investigated for a panel of human cancer cell lines of different histotypes. Five of these cancer cells were adherent; skin melanoma A375, lung carcinoma A549, hepatocellular carcinoma HepG2, breast carcinoma MCF-7, and prostate carcinoma PC-3; and one was in suspension, acute promyelocytic leukemia HL-60. Values of $\mathrm{IC}_{50}$, i.e. the concentration of the extract required to inhibit cell growth by $50 \%$ of the control level, for each of these cancer cells was estimated from the corresponding concentration-and-growth-inhibition plot. The $\mathrm{IC}_{50}$ values after $48 \mathrm{~h}$ of treatment are shown in Table I. It seemed that the growth-inhibitory effect of the EA extract was selective as it did not retard growth of the lung and prostate cancer cells $\left(\mathrm{IC}_{50}>1000 \mu \mathrm{g} / \mathrm{ml}\right)$. On the other hand, of all the cancer cell lines tested in this study, HL-60 was found to be the most responsive $\left(\mathrm{IC}_{50}=58 \mu \mathrm{g} / \mathrm{ml}\right)$, compared to the others $\left(\mathrm{IC}_{50}>170 \mu \mathrm{g} / \mathrm{ml}\right)$. Therefore, mechanisms for the growth inhibition were further investigated in the leukemic cell line.

The EA extract induces $S$ phase arrest followed by apoptosis in HL-60 cells. To investigate the mechanisms for growth inhibition, HL-60 cells were incubated with the extract at $\mathrm{IC}_{50}$ for 24-96 h. Cells in different cell cycle phases and in apoptosis were then determined with DNA-PI flow cytometry. The extract arrested S phase cells from 24-72 h, accompanied by decreases in $G_{1}$ phase cells (Fig. 1). Strikingly, cells undergoing apoptosis with fragmented DNA (appearing as a $\mathrm{subG}_{1}$ peak in the DNA histogram) were observed at $72 \mathrm{~h}$ following the $S$ phase arrest. Furthermore, the number of apoptotic cells was elevated time dependently, so that they were increased by 4 -fold of the control level at $72 \mathrm{~h}$ and by 35 -fold at $96 \mathrm{~h}$ of treatment.

The pro-apoptotic activity of the EA extract of S. glabra was further confirmed by using annexin V/PI flow cytometry. At $48 \mathrm{~h}$ of treatment with EA extract at $\mathrm{IC}_{50}$, early-phase apoptotic cells were elevated by $330 \%$ and late-phase apoptotic cells (or necrotic cells) were increased by $70 \%$ of the control levels (Fig. 2a and b). Comparable to the above DNA study, results from the annexin study also illustrated that the pro-apoptotic activity of the extract was timedependent, so that the early- and late-phase apoptotic cells at $72 \mathrm{~h}$ of treatment were increased by $2210 \%$ and $593 \%$, respectively (Fig. 2c and d).

The EA extract elevates pro-apoptotic Bax/Bcl-2 ratio in HL-60 cells. Pro-apoptotic Bax and anti-apoptotic Bcl-2 are two members of the Bcl-2 family that regulate the mitochondrial pathway in apoptosis (12). These proteins interact so that their relative abundance has been implicated in the sensitization of leukemic cells to apoptotic stimuli (15). In this study, Bax and Bcl-2 protein levels in HL-60 cells were measured semi-quantitatively with immunoblotting and densitometry. At $48 \mathrm{~h}$ of treatment with EA extract at $\mathrm{IC}_{50}$, bcl-2 was down-regulated by $13 \%$ and bax was up-regulated by $65 \%$ so that the pro-apoptotic $\mathrm{Bax} / \mathrm{Bcl}-2$ protein ratio was elevated by $90 \%$, compared to the control (Fig. 3). Although the extract did not continue up-regulating Bax expression at $72 \mathrm{~h}, \mathrm{Bcl}-2$ protein was down-regulated prominently by $>63 \%$, so that the bax/bcl-2 ratio was elevated dramatically
(A)
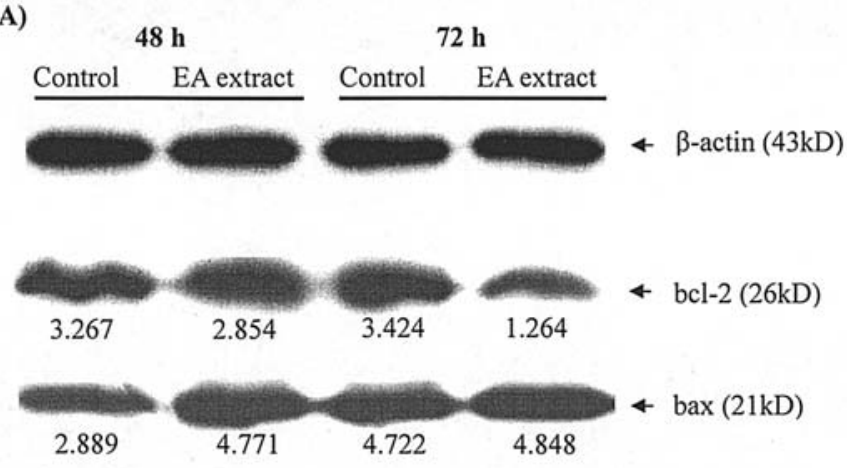

(B)

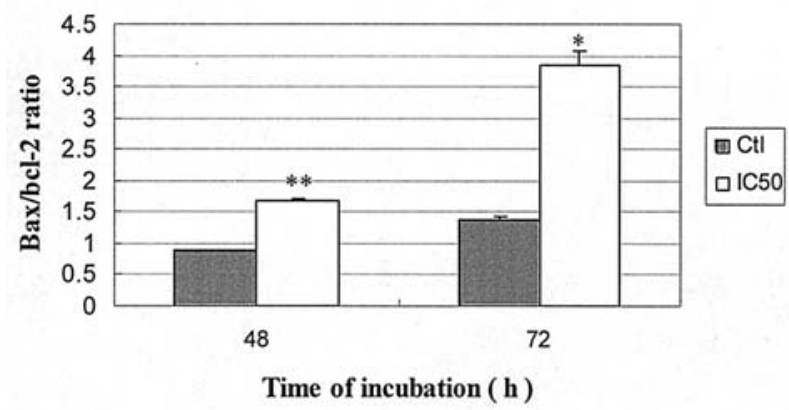

Figure 3. Effects of the EA extract on Bcl-2 and Bax expression in HL-60 cells. The leukemic cells were incubated in the absence, i.e., control, or in the presence of the EA extract at $\mathrm{IC}_{50}$ for 48 and $72 \mathrm{~h}$. Anti-apoptotic Bcl-2 and pro-apoptotic Bax proteins in the cell lysate were then measured semiquantitatively with immunoblotting and densitometry. (Panel A) The extract mildly up-regulated Bax and down-regulated Bcl-2 protein at $48 \mathrm{~h}$, followed by prominent depletion of Bcl-2 protein only at $72 \mathrm{~h}$. $\beta$-actin was also measured for normalizing expression of other proteins. Densitometric readings of the Bax and Bcl-2 protein bands are also shown. (Panel B) Based on the readings from densitometry, pro-apoptotic $\mathrm{Bax} / \mathrm{Bcl}-2$ protein ratio was also calculated, showing that the extract might up-regulate this ratio to sensitize the leukemic cells to apoptotic stimuli. Results are expressed as mean \pm SD of three independent experiments. ${ }^{*} \mathrm{p}<0.05$ and ${ }^{* *} \mathrm{p}<0.01$, compared to the corresponding time control by Student's t-test.

by $>178 \%$ of the control level. Therefore, induction of apoptosis in HL-60 cells at 48 and $72 \mathrm{~h}$ of treatment with the EA extract of $S$. glabra was associated with elevation of the pro-apoptotic Bax/Bcl-2 protein ratio, suggesting that the extract may up-regulate the ratio to sensitize the leukemic cells to apoptotic stimuli.

\section{Discussion}

The efficacy of traditional Chinese medicine (TCM) is beyond doubt, since it has been used clinically for thousands of years in China for treating various kinds of diseases. However, the lack of scientific proof on the mode of action of TCM has become the major impediment in its modernization and introduction to the western countries. Therefore, analysis of the bioactive ingredients and elucidation of the mechanisms involved in TCM therapies are crucial in paving the road for developing new pharmaceuticals from TCM.

Sarcandra glabra is an important herb used in TCM formulations. With reported anti-tumor, anti-inflammatory and anti-viral activities (2-6), S. glabra has recently been 
refined and developed as an over-the-counter pharmaceutical and nutraceutical in China (2). In addition to its efficacy toward various diseases, S. glabra was proven to be non-toxic with acute toxicity, murine sperm malformation, and Ames tests (3). However, the modes of action for its anti-tumor and other pharmacological properties are still largely unknown. Therefore, before S. glabra is further developed as an antitumor agent, the anti-tumor activities and mechanisms of its bioactive ingredients should firstly be elucidated.

We demonstrated in this study for the first time that the EA extract of $S$. glabra retarded the growth of cancer cells selectively; of all the human cancers of different histotypes tested in this study, leukemic HL-60 was found to be the most responsive to the growth inhibition. The DNA study further illustrated that the extract seemed to interfere with DNA replication and thus arrested cell cycle progression at $\mathrm{S}$ phase in the leukemic cells, followed by apoptosis induction. The pro-apoptotic activity of the EA extract of S. glabra was further evidenced by the loss of phospholipid asymmetry in the plasma membrane of the leukemic cells. Apoptosis is a control mechanism that regulates the balance between cell proliferation and cell death for achieving normal tissue homeostasis (25). Defects in apoptotic pathways have been identified as one of the major causes of malignancies $(7,26)$. Many contemporary anti-cancer approaches, such as radiotherapy, chemotherapy, and immunotherapy, exert their therapeutic actions through apoptosis mediation in the target cells (27). The initiation of apoptosis is functionally characterized by the mitochondrial membrane permeabilization (MMP), in which both Bcl-2 and Bax have played crucial roles. Bcl-2 is an anti-apoptotic, membrane-associated protein that is present in the endoplasmic reticulum and the nuclear and outer mitochondrial membranes. It participates in the formation of transient pore complex and protects cells from apoptosis induced by survival factor removal and cytocidal effects of a variety of toxic agents by stabilizing the mitochondrial membrane via the formation of Bcl-2 homodimers $(19,28)$. Bax, on the contrary, stimulates release of apoptogenic molecules from mitochondria either by heterodimerizing with bcl-2 and thereby hinders the stabilizing effect of Bcl-2 homodimers on the mitochondrial membrane, or by direct induction of MMP $(20,21)$. The released apoptogenic molecules, such as cytochrome $c$, AIF, and EndoG, initiate the apoptotic cascades, leading to the various biochemical and morphological changes in apoptotic cells (15). Therefore, the relative abundance of Bax and Bcl2 proteins determines the cellular sensitization to apoptotic stimuli $(12,15)$. Our results showed that the EA extract of $S$. glabra induced elevation of the pro-apoptotic Bax/Bcl-2 protein ratio at the time of or prior to the loss of phospholipid asymmetry and DNA fragmentation in the apoptotic cells, suggesting that the bioactive ingredients in the extract might have induced MMP and the release of apoptogenic molecules from mitochondria. The leukemic cells were thus sensitized and apoptosis was induced.

In conclusion, our findings support the previous report that the anti-cancer activity of $S$. glabra is particularly prominent on leukemia (3). Results from this scientific study further show that the bioactive ingredients in EA extract of $S$. glabra may exert an anti-cancer effect at least by inducing cell cycle arrest and apoptosis. In order to identify the actual efficacious components, further purification of the bioactive ingredients in EA extract should be performed. Further elucidation of the apoptosis signaling pathways can also help to depict the modes of action of S. glabra for its anti-cancer property. Although $S$. glabra has been previously shown to be non-toxic (3) and its EA extract was found in this study to have selective growth inhibitions on certain human cancers only, preclinical studies are still required to evaluate its toxicity to animals and to normal human tissues before it is clinically introduced for treating cancers.

\section{Acknowledgements}

We sincerely thank Professor S.Y. Hu for the plant authentication. The work described in this paper was supported by grants from the Research Grants Council, The Hong Kong Special Administrative Region.

\section{References}

1. Abelson PH: Medicine from plants. Science 247: 513, 1990.

2. Liu AW, Lou YM and Lin YH: The progress of study on Caoshanhu and plants of the same category. J Tradit Chin Med 4: 50-53, 2002.

3. Wang GL, Chen DF and Lin RC: Advances in studies on chemical constituents and its quality control of whole plant of Sarcandra glabra. Zhong cao yao 34: S12-S14, 2003.

4. Zhang W, Wang S, Chen X and Hu Z: Analysis of Sarcandra glabra and its medicinal preparations by capillary electrophoresis. Talanta 60: 955-960, 2003.

5. Zhou G, Liu H, Wang H and Kuang P: Determination of isofraxidin in Sarcandra glabra (Thunb.) Nakai by HPLC. Zhongguo Zhong Yao Za Zhi 24: 481-502, 1999.

6. Jiang W, Kong X and Liang G: Effects of Tabellae sarcandrea on malignant tumor and immunity. Guangxi Yi Ke Da Xue Xue Bao 18: 39-41, 2001.

7. Ghobrial IM, Witzig TE and Adjei AA: Targeting apoptosis pathway in cancer therapy. CA Cancer J Clin 55: 178-194, 2005.

8. Chan SL and Yu VC: Proteins of the Bcl-2 family in the apoptosis signalling: from mechanistics insights to therapeutic opportunities. Clin Exp Pharmacol Physiol 31: 119-128, 2004.

9. Fadok VA, Voelker DR, Campell PA, Cohen JJ, Bratton DL and Henson PM: Exposure of phosphatidylserine on the surface of apoptotic lymphocytes triggers specific recognition and removal by macrophages. J Immunol 148: 2207-2216, 1992.

10. Vermes I, Haanen C, Steffens-Nakken H and Reutelingsperger C: A novel assay for apoptosis. Flow cytometric detection of phosphatidylserine expression on early apoptotic cells using fluorescein labelled Annexin V. J Immunol Methods 184: 39-51, 1995.

11. Wyllie AH, Kerr JF and Currie AR: Cell death: the significance of apoptosis. Int Rev Cytol 68: 251-306, 1980.

12. Tudor G, Aguilera A, Halverson DO, Laing ND and Sauvile EA: Susceptibility to drug induced apoptosis correlates with differential modulation of Bad, Bcl-2 and Bcl-XL protein levels. Cell Death Differ 7: 574-586, 2000.

13. Green DR and Evan GI: A matter of life and death. Cancer Cell 1: 19-30, 2002.

14. Gross A, McDonnell JM and Korsmeyer SJ: BCL-2 family members and the mitochondria in apoptosis. Genes Dev 13: 1899-1911, 1999.

15. Kuwana T and Newmeyer DD: Bcl-2-family proteins and the role of mitochondria in apoptosis. Curr Opin Cell Biol 15: 691-699, 2003.

16. Newmeyer DD and Ferguson-Miller S: Mitochondria: releasing power for life and unleashing the machineries of death. Cell 112: 481-490, 2003

17. Hockenberry D, Nunez G, Milliman C, Schreiber RD and Korsmeyer SJ: Bcl-2 as an inner mitochondrial membrane protein that blocks programmed cell death. Nature 348: 334336,1990 . 
18. Krajewski S, Tanaka S, Takayama S, Schibler MJ, Fenton W and Reed JC: Investigations of the subcellular distribution of the bcl-2 oncoprotein: residence in the nuclear envelope, endoplasmic reticulum, and the outer mitochondrial membranes. Cancer Res 53: 4701-4714, 1993.

19. Bowen ID, Bowen SM and Jones AH: The genetic basis of programmed cell death. In: Mitosis and Apoptosis: Matters of Life and Death. Bowen ID, Bowen SM and Jones AH (eds). Chapman \& Hall, London, pp60-99, 1998.

20. Moriishi K, Huang DC, Cory S and Adams JM: Bcl-2 family members do not inhibit apoptosis by binding the caspase activator apaf-1. Proc Natl Acad Sci USA 96: 9683-9688, 1999.

21. Newmeyer DD, Bossy-Wetzl E, Kluck RM, Wolf BB, Beere HM and Green DR: BclxL does not inhibit the function of Apaf-1. Cell Death Differ 7: 402-407, 2000

22. Manon S, Chaudhuri B and Guerin M: Release of cytochrome c and decrease of cytochrome c oxidase in Bax-expressing yeast cells, and prevention of these effects by coexpression of Bcl-xL. FEBS Lett 415: 29-32, 1997.
23. Rosse T, Olivier R, Monney L, Rager M, Conus S, Fellay I, Janson B and Borner C: Bcl-2 prolongs cell survival after Baxinduced release of cytochrome c. Nature 391: 496-499, 1998.

24. Oltvai ZN and Korsmeyer SJ: Check point of dueling dimmers foil death wishes. Cell 79: 189-192, 1994.

25. Evan GI and Vousden KH: Proliferation, cell cycle and apoptosis in cancer. Nature 411: 342-348, 2001.

26. Fisher U and Schulze-Osthoff K: New approaches and therapeutics targeting apoptosis in disease. Pharmacol Rev 57: 187-215, 2005.

27. Lockshin RA and Zakeri Z: When cells die II: a comprehensive evaluation of apoptosis and programmed cell death. In: Cell Death in Cancer and Cancer Therapy. Fulda S and Debatin KM (eds). John Wiley and Sons, Hoboken, NJ, pp461-482, 2004.

28. Crompton M: The mitochondrial permeability transition pore and its role in cell death. Biochem J 341: 233-249, 1999. 